\title{
Short Communication: \\ Molecular barcode and morphology analysis of Malva pseudolavatera Webb \& Berthel and Malva sylvestris L. from Ecuador
}

\author{
GLENDA SARMIENTO-TOMALÁ ${ }^{1, \nu}$, EFRÉN SANTOS-ORDÓÑEZ ${ }^{2,3, v \vee}$, MIGDALIA MIRANDA-MARTÍNEZ ${ }^{4}$, \\ RICARDO PACHECO-COELLO ${ }^{2}$, RAMÓN SCULL-LIZAMA ${ }^{5}$, YAMILET GUTIÉRREZ-GAITÉN ${ }^{5}$, \\ RENÉ DELGADO-HERNÁNDEZ ${ }^{5}$ \\ ${ }^{1}$ Universidad de Guayaquil. Facultad de Ciencias Químicas. Ciudadela Universitaria "Salvador Allende". Ave. Kennedy S/N y Av. Delta. Guayaquil. \\ Ecuador. Tel./fax.: + 5934229 3680. "email: glenda.sarmientot@ug.edu.ec \\ ${ }^{2}$ ESPOL Polytechnic University, Escuela Superior Politécnica del Litoral, ESPOL, Centro de Investigaciones Biotecnológicas del Ecuador, Campus \\ Gustavo Galindo, Km. 30.5 vía Perimetral, P.O. Box 09-01-5863, Guayaquil, Ecuador. Tel./fax.: +5934 226 9610. "`email: gsantos@espol.edu.ec \\ ${ }^{3}$ ESPOL Polytechnic University, Escuela Superior Politécnica del Litoral, ESPOL, Facultad de Ciencias de la Vida, Campus Gustavo Galindo, Km. 30.5 \\ vía Perimetral, P.O. Box 09-01-5863 Guayaquil, Ecuador \\ ${ }^{4}$ ESPOL Polytechnic University, Escuela Superior Politécnica del Litoral, ESPOL, Facultad de Ciencias Naturales y Matemáticas. Departamento de \\ Ciencias Químicas y Ambientales. Campus Gustavo Galindo. Km 30.5 vía Perimetral. Guayaquil. Ecuador \\ ${ }^{5}$ Instituto de Farmacia y Alimentos, Universidad de la Habana. 222 y Ave 23, La Coronela, La Lisa, Ciudad Habana, Cuba
}

Manuscript received: 12 June 2020. Revision accepted: 12 July 2020.

\begin{abstract}
Sarmiento-Tomalá G, Santos-Ordóñez E, Miranda-Martínez M, Pacheco-Coello R, Scull-Lizama R, Gutiérrez-Gaitén Y, Delgado-Hernández R. 2020. Short Communication: Molecular barcode and morphology analysis of Malva pseudolavatera Webb \& Berthel and Malva sylvestris L from Ecuador. Biodiversitas 21: 3554-3561. In Ecuador, several plant species are used in traditional medicine without a criterion of family, genera, or chemical composition. The species of the genus Malva (Malva pseudolavatera Webb \& Berthel and Malva sylvestris L), introduced in Ecuador, are widely used by the population; however, unlike the species M. sylvestris, for M. pseudolavatera there is no information about its composition and properties. Plant material was collected in the province of Chimborazo in Ecuador and taxonomic classification was performed. Histological study was performed in leaves and powder drug. Molecular barcodes were generated using the ribulose bisphosphate carboxylase large chain $(r b c \mathrm{~L})$, maturase $\mathrm{K}$ (matK), internal transcribed spacer 1 (ITS1) and ITS2 sequences. Micro-morphological analysis revealed that no major structural differences were observed between the two species. Sequence analysis of molecular barcodes revealed that samples of the different species showed a close relation to each other due to the high percentage of similarity. The ITS sequences showed that the two samples correspond to different species of Malva; while for the $r b c \mathrm{~L}$ and $m a t \mathrm{~K}$, interspecies differentiation could not be detected. Therefore, ITS could be used for interspecific analysis.
\end{abstract}

Keywords: Internal Transcribed Spacer, ITS1, ITS2, matK, micromorphology, molecular markers, $r b c \mathrm{~L}$

Abbreviations: CTAB: Cetrimonium bromide, ITS: internal transcribed spacer, matK: maturase K, PCR: polymerase chain reaction, $r b c \mathrm{~L}$ : ribulose bisphosphate carboxylase large chain

\section{INTRODUCTION}

The genus Malva includes some 30 species and is found in temperate, subtropical, and tropical zones of Africa, Asia, and Europe and has been introduced all over the Americas. The genus Malva belongs to the subfamily Malvoideae which consists of 78 genera and 1670 species. In Ecuador, some species of Malva are used for traditional medicine, including i) white Malva (Althaea officinalis); ii) Malva sylvestris L.; and, iii) Malva pseudolavatera Webb $\&$ Berthel (de la Torre et al. 2008). Among the species that are commercialized, the one with the highest consumption is Malva pseudolavatera (de la Torre et al. 2008). Many species of the genus Malva are used for medicinal application, but among these, Malva sylvestris revealed several reports regarding traditional medicine usage and food consumption (Gasparetto et al. 2012; Razavi et al.
2011; Nasiri et al. 2015; Mofid et al. 2015). Various chemical components have been reported for M. sylvestris. Through the use of high-performance liquid chromatography, the presence of amino acids was detected including alanine, threonine, hydroxyproline, serine, glutamine, asparagine, and arginine; while the presence of trigonelline and glycine betaine was described in the leaves, flowers and roots, respectively (Blunden et al. 2001). On the other hand, information in the literature about composition and properties for the species Malva pseudolavatera is limited. Furthermore, in Ecuador, this specie is widely used by the population for purposes similar to Malva sylvestris. Although Malva plants are used as traditional medicine in Ecuador, morphological and molecular barcodes analysis is lacking. The use of molecular barcodes could complement the morphological and taxonomic studies of the $M$. sylvestris and $M$. 
pseudolavatera in Ecuador. Molecular barcodes could be used in biodiversity analysis, ecological studies, and other applications (Ajmal et al. 2014). The use of molecular barcodes will aid taxonomists for species discovery and differentiation (Hebert et al. 2003). Furthermore, identification in markets of plant species is challenging as the plant tissues are often dried or in a processed form; therefore, the use of different molecular barcodes could be used for proper identification and differentiation between plant species, where in combination with morphology and traditional knowledge of plants, could optimize the identification (Ghorbani et al. 2017). Therefore, the use of molecular barcoding as an integrated approach with taxonomy analysis increases efficiency for species identification (Dasmahapatra and Mallet 2006; Ajmal et al. 2014). Different molecular barcodes including $r b c \mathrm{~L}, \mathrm{mat} \mathrm{K}$, ITS1, and ITS2 are used in the characterization of medicinal plants (reviewed by Techen et al. 2014). While the use of the barcodes $r b c \mathrm{~L}$ and $m a t \mathrm{~K}$ are relevant for the identification of genera, differentiation at the species level from the same genus could be difficult. On the other hand, the ITS1 and ITS2 barcodes could give a better resolution (Techen et al. 2014; Zhang et al. 2016). The purpose of this study is to identify polymorphisms in barcode sequences between $M$. sylvestris and $M$. pseudolavatera of the different molecular barcodes tested. This study reports the micro-morphological and comparative molecular barcodes of these two species of Malva, that could be used for further chemical, pharmacological and phylogenetic studies. For the first time, the molecular barcodes of $r b c \mathrm{~L}$, matK, ITS1 and ITS2 from $M$. sylvestris and $M$. pseudolavatera from Ecuador was determined.

\section{MATERIALS AND METHODS}

\section{Collection of plant material}

The plant material (M. sylvestris and M. pseudolavatera leaves), was collected during the month of May 2018 in Riobamba city, Chimborazo province, located in the geographic center of Ecuador, in the Andes mountains at 2,750 meters above sea level with the following coordinates: $1^{\circ} 40^{\prime} 15.5^{\prime \prime} \mathrm{S} 78^{\circ} 38^{\prime} 49.6^{\prime \prime O}$. The average temperature of the area is $13^{\circ} \mathrm{C}$, with a humidity of $71 \%$, and $22 \%$ of annual rainfall. The collection was made from crops grown from farmers. The crop production is available from local markets; therefore, additional permissions are not needed. One sample of each specie was delivered to the herbarium of the Faculty of Natural Sciences of the University of Guayaquil, Ecuador for taxonomic characterization which was herbalized and assigned herbarium numbers, corresponding to 13118 and 13119. Identification as species from the genus Malva was performed by M.Sc. Xavier Cornejo.

\section{Micro-morphology}

For the histological analysis, cross-sections of the leaves were made in fresh tissues manually, which were hydrated and rinsed with $1 \%$ sodium hypochlorite. Tissues were stained with $1 \%$ safranin in water, and fixed with glycerinated gelatin, according to the procedures described by Gattuso and Gattuso (1999). To observe the anatomical details at the level of the epidermis of the leaf, the diaphanizantion technique was performed. The sample was rinsed with sodium hypochlorite solution, then washed with distilled water and colored with $1 \%$ safranin in water (Miranda and Cuéllar 2000). The microscopic characteristics of the powder drug were determined. The samples were rinsed with sodium hypochlorite and after washing, the samples were stained with $1 \%$ safranin to finally be fixed in glycerinated gelatin as described above. To visualize the different internal anatomical characters of the plant, a NOVEL microscope (10X lens) coupled with a camera model HDCE-50B was used.

\section{DNA extraction and Polymerase Chain Reaction (PCR)}

Leaves from collected samples (M. sylvestris and $M$. pseudolavatera), from one specimen each, were ground using liquid nitrogen in the grinder MM400 (Retsch) and stored at $-80^{\circ} \mathrm{C}$ upon DNA extraction. Approximately 100 $\mathrm{mg}$ of leaf was used for DNA extraction using a Cetrimonium bromide (CTAB) protocol with some modifications (Pacheco Coello et al. 2017). PCR was performed using the $2 \mathrm{x}$ GoTaq ${ }^{\circledR}$ master mix (Cat. \# M7123, Promega) using $0.5 \mu \mathrm{M}$ of each primer (Table 1). The final volume was $50 \mu \mathrm{l}$ per reaction. PCR conditions were $95^{\circ} \mathrm{C}$ for $3 \mathrm{~min}$ for initial denaturation; 35 cycles of $95^{\circ} \mathrm{C}$ for $30 \mathrm{~s}, 60^{\circ} \mathrm{C}$ [for ribulose bisphosphate carboxylase large chain $(r b c \mathrm{~L})$ ] or $56^{\circ} \mathrm{C}$ [for maturase $\mathrm{K}($ mat $\mathrm{K})$, internal transcribed spacer 1 (ITS1) and internal transcribed spacer 2 (ITS2)] for $30 \mathrm{~s}, 72^{\circ} \mathrm{C}$ for $90 \mathrm{~s}$, with a final extension of $72^{\circ} \mathrm{C}$ for $5 \mathrm{~min}$. Five microliters of PCR reaction was loaded on a $1.5 \%$ gel to check for the amplicons. The remaining $45 \mu \mathrm{l}$ were purified using the Wizard SV Gel and PCR Clean-Up System (Cat. \# A9282, Promega) and sequenced commercially (Macrogen, Maryland, USA). At least three technical replicates (independent PCR reactions from isolated DNA) were sequenced and a consensus sequence was developed. The sequences were deposited at the GenBank (Table 2).

\section{Bioinformatic analysis of sequences}

Sequences were trimmed from low quality using Chromas (Technelysium). Public available barcode sequences from the Malvoideae were queried in the GenBank database $\left(29^{\text {th }}\right.$ May 2020) and used in phylogenetic analysis using MEGAX (Stecher et al. 2020). Furthermore, for the $r b c \mathrm{~L}$ and mat $\mathrm{K}$ barcode sequence, the recommended model after analysis of the queried sequences using MEGAX was used after alignment with MUSCLE. For the phylogenetic analyses, the Maximum Likelihood method was used for each barcode using bootstrap test (100 replicates). To compare the analysis with different genera from the Malvoideae subfamily, three accessions from the Alcea and the Althae genera were used in the phylogenetic analysis for each barcode. 
Table 1. Primers used for amplification of $r b c \mathrm{~L}$, matK, ITS1 and ITS2. PCR was performed according to Bustamante et al. (2019)

\begin{tabular}{|c|c|c|c|c|}
\hline Primer pairs & Sequence & $\begin{array}{l}\text { Expected } \\
\text { size (bp) }\end{array}$ & Region & Reference \\
\hline rbcLA_F rbcLA_R & $\begin{array}{l}\text { 5'ATGTCACCACAAACAGAGACTAAAGC3' } \\
\text { 5'GTAAAATCAAGTCCACCRCG3' }\end{array}$ & 550 & $r b c \mathrm{~L}$ & Costion et al. 2011 \\
\hline $\begin{array}{l}\text { matK_3F_KIMf } \\
\text { matK_1R_KIM R }\end{array}$ & $\begin{array}{l}\text { 5'CGTACAGTACTTTTGTGTTTACGAG3' } \\
\text { 5'ACCCAGTCCATCTGGAAATCTTGGTTC3' }\end{array}$ & 850 & matK & Costion et al. 2011 \\
\hline $\begin{array}{l}\text { ITS } 5 \overline{\mathrm{a} F} \\
\text { ITS } 4 \mathrm{R}\end{array}$ & $\begin{array}{l}\text { 5'CCTTATCATTTAGAGGAAGGAG3' } \\
\text { 5'TCCTCCGCTTATTGATATGC3' }\end{array}$ & 700 & ITS1 & Cheng et al. 2016 \\
\hline $\begin{array}{l}\text { S2F } \\
\text { S3R }\end{array}$ & $\begin{array}{l}\text { 5'ATGCGATACTTGGTGTGAAT3' } \\
\text { 5'GACGCTTCTCCAGACTACAAT3' }\end{array}$ & 400 & ITS2 & Cheng et al. 2016 \\
\hline
\end{tabular}

Table 2. Samples and sequences submitted in the GenBank

\begin{tabular}{lll}
\hline Species & Barcode & $\begin{array}{l}\text { Accession } \\
\text { number }\end{array}$ \\
\hline M. sylvestris & $r b c \mathrm{~L}$ & MH078523 \\
& matK & MH078524 \\
& ITS1 & MH513582 \\
& ITS2 & MH517024 \\
M. pseudolavatera & $r b c \mathrm{~L}$ & MH025945 \\
& matK & MH078525 \\
& ITS1 & MH513499 \\
& ITS2 & MH513596 \\
\hline
\end{tabular}

The ITS sequences from Malva pseudolavatera with the accession numbers MH513499, MH513596 and Malva sylvestris with the accession numbers MH513582, MH517024 were concatenated to fit a partial region of the ITS and used for the alignment to determinate variable sites. Phylogenetic analysis was performed as described above for the concatenated ITS sequences from both Malva species.

\section{RESULTS AND DISCUSSION}

\section{Micro-morphology of Malva sylvestris}

The cross-section at the level of the central nerve (Figure 1A) of the wild mallow leaf showed a concave shape in the lower part, while the epidermis of that face is provided with abundant star-shaped trichomes. A stratified mono epidermis is observed followed by the collenchyma tissue, which is not very well differentiated, next to spongy parenchyma; while in the center, the conductive vessels (xylem and phloem) that cross of the marrow is depicted. In the lateral arms of the mesophyll (Figure 1B and 1C), the abundance of trichomes in starry shape (Figure 1D) could denote a characteristic of this species. In both surfaces (adaxial and abaxial) the epidermis formed by tabular cells is more noticeable in the upper one, where the vestiges of hairs that were truncated during the analysis process were observed, followed by a palisade tissue that continues with the spongy parenchyma. The enlarged view of the trichomes (Figure 1D) showed the abundance of these structures depicting in the center a more pigmented area. A diaphanized analysis of the surface of the adaxial epidermis (Figure 1E) show the cells in polygonal shapes, abundance of trichomes in the form of stars, and a set of black dots is maintained.
The analysis of the drug in powder turned into sinuous epidermal cells with the anisocytic or cruciferous type (Figure 2A). Remains of epidermis formed by polygonal cells and abundant trichomes were observed (Figure 2B). A conductive vessel (xylem) of the scalariform type, and a set of structures that supposedly may correspond to calcium oxalate crystals of the rosette type is shown (Figure 2C). For this specie, Romitelli and Martins (2013) report the micro-morphological characteristics of both the leaf and the powder drug, and marked differences were not found between the species studied and in the reported literature.

\section{Micro-morphology of Malva pseudolavatera}

In general terms, no major structural differences were observed in comparison with $M$. sylvestris, except that at the intervals fewer elements forming the cluster of hairs in the shape of a star were observed, which is very well represented in $M$. sylvestris. The black points or structures became apparent, and sometimes the crystals are presented in the form of rosettes. The cross-section at the level of the central nerve of the leaf (Figure 3A), showed in the upper part a convex shape and in the lower one a concave shape. The epidermis of these faces is provided with few starshaped trichomes. An epidermis with a cellular stratum is observed, followed by the collenchyma formed by compact cells. Afterward, the spongy parenchyma appears, and in the center the vascular bundles (xylem and phloem) appeared. A view of the lateral arm of the mesophyll (Figure 3B) showed trichomes with a different conformation and lower abundance than in M. sylvestris, grouped of 2 to 3 pieces. In both surfaces (adaxial and abaxial), the epidermis formed by tabular cells is appreciated, more noticeable in the upper one, followed by palisade tissue. The palisade tissue and the spongy parenchyma could also be observed. An analysis of the diaphanization of the abaxial epidermis (Figure 3C) of the leaf showed slightly sinuous cells with anisocytic or cruciferous stomata (three attached cells and a smaller one). The enlarged view of the trichomes (Figure 3D) showed the grouping of these structures with a semi-solid form, unlike $M$. sylvestris, the junction point is not pigmented. The analysis of the powder drug (Figure 4), showed slightly sinuous polygonal epidermal cells (Figure 4A). The forming elements of the semi-crashed structure of the hairs as well as the black points or structures (Figure 4B) were also observed. 


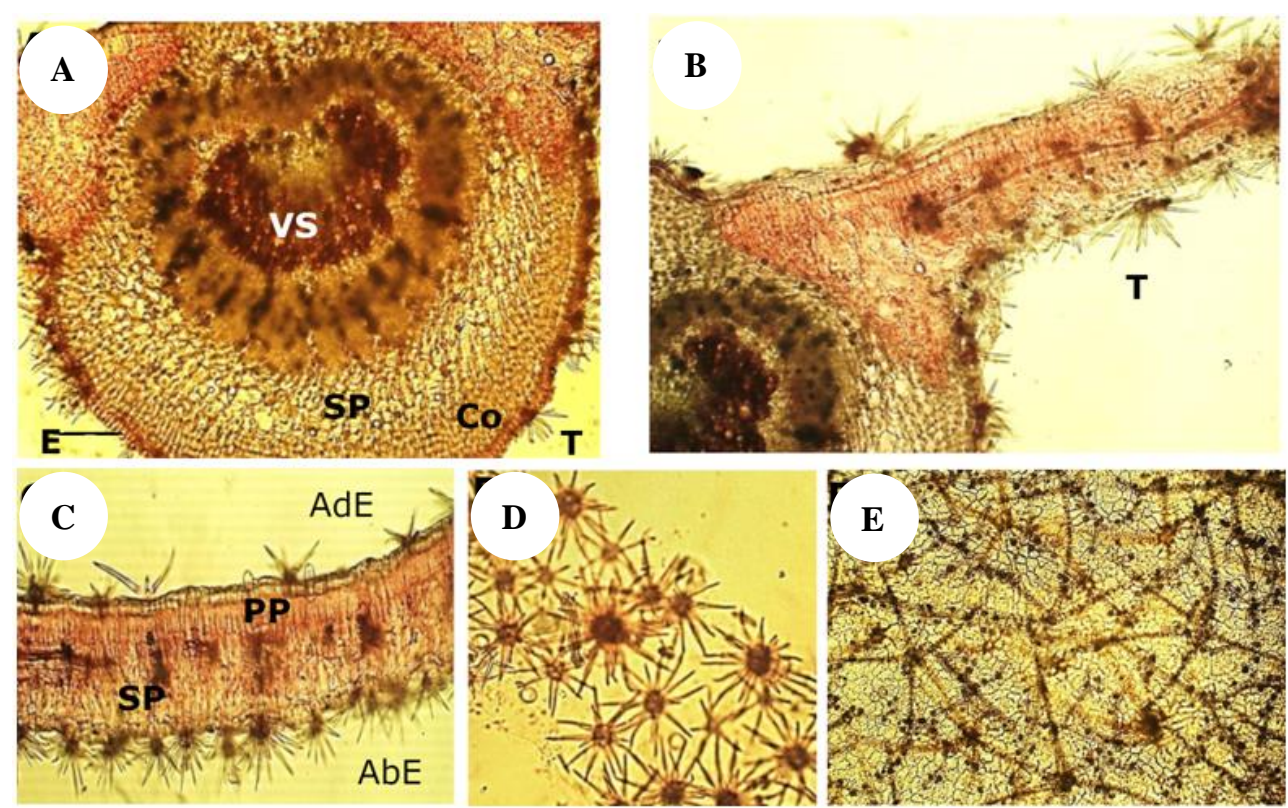

Figure 1. Transversal section of the central nerve of the leaf and diaphanized from Malva sylvestris L. (A) Central nerve. (B) Mesophyll. (C) Enlarged view of the mesophyll. (D) Trichomes. (E) Adaxial epidermis. E: epidermis, SP: spongy parenchyma, Co: collenchyma, VS: vascular system, T: trichomes, AbE: abaxial epidermis, PP: palisade parenchyma, AdE: adaxial epidermis.
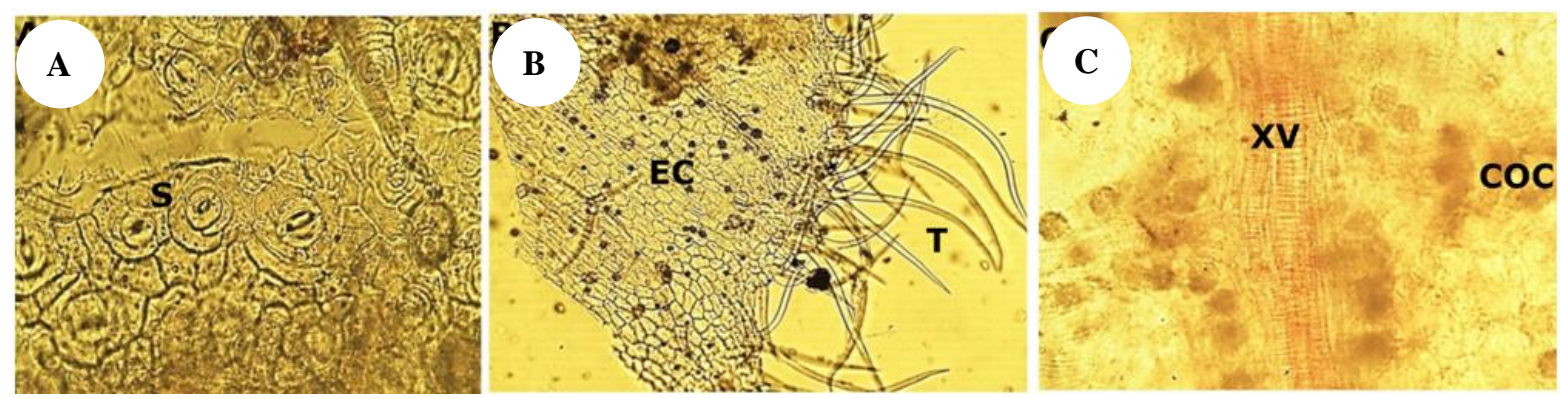

Figure 2. Micro-morphological details of the powder drug from Malva sylvestris L. (A) Stomata. (B) Epidermal cells and trichomes. (C) Xylematic vessels and crystals S: stomata, T: trichomes, EC: epidermal cells, XV: xylematic vessels, COC: calcium oxalate crystal
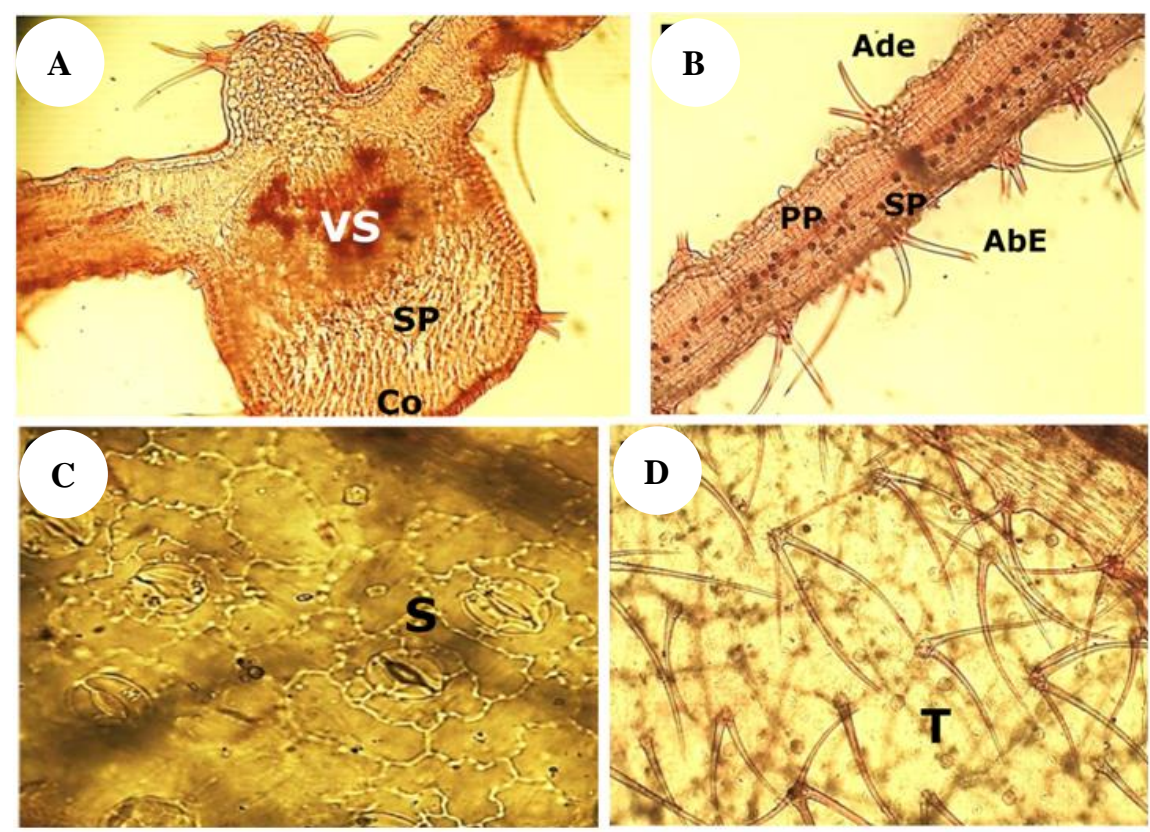

Figure 3. Transversal section of the central nerve of the leaf and diaphanized from Malva pseudolavatera Webb \& Berthel. (A) Central nerve. (B) Mesophyll. (C) abaxial epidermis and stomata. (D) Trichomes. E: epidermis, Co: collenchyma, SP: spongy parenchyma, VS: vascular system, AbE: abaxial epidermis, PP: palisade parenchyma, Ade: adaxial epidermis, S: stomata, T: trichomes. 

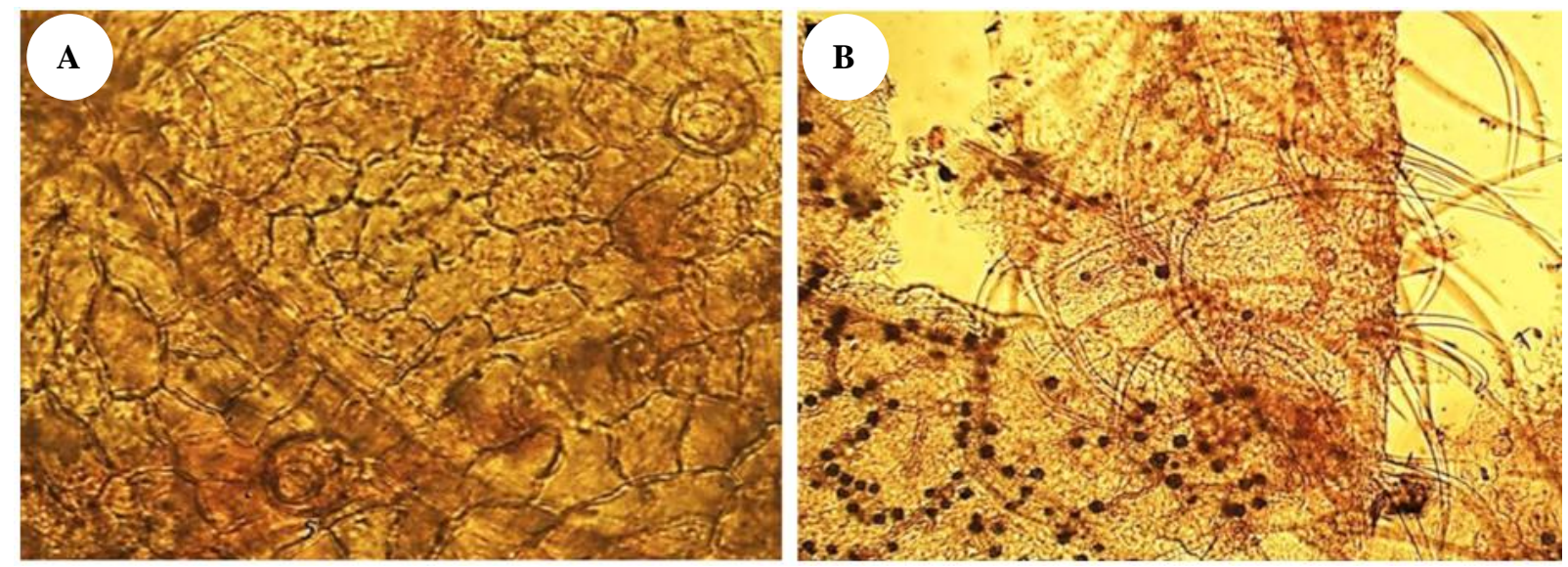

Figure 4. Micro-morphological details of the powder drug from Malva pseudolavatera Webb \& Berthel. (A) Epidermal cells. (B) Epidermal cells and trichomes

A

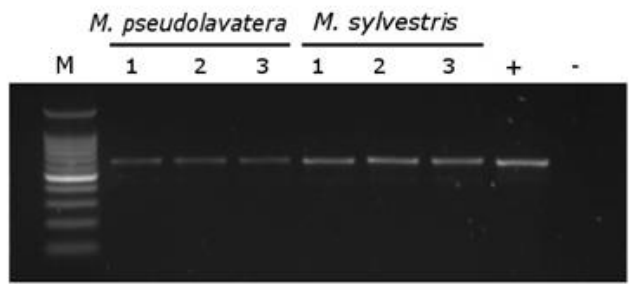

B

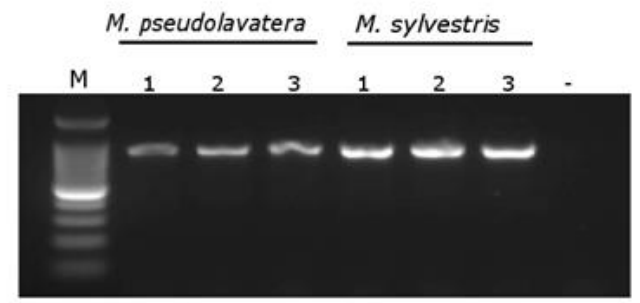

C M. pseudolavatera M. sylvestris

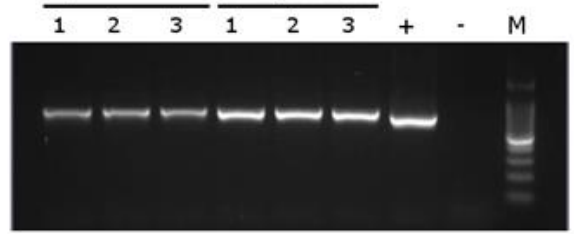

$\mathbf{D}$

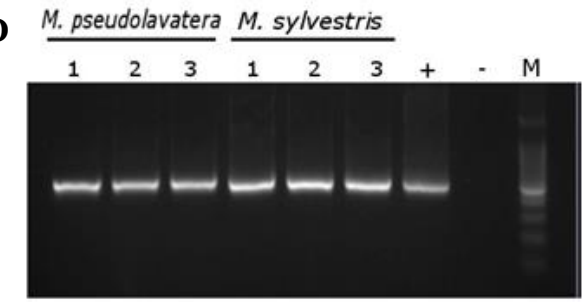

Figure 5. Gel electrophoresis of amplicons generated for the molecular barcodes with the genomic DNA of Malva pseudolavatera and Malva sylvestris. A. Amplification of rbcL A_F/ rbcL A_R. B. Amplification of matK_3F_KIM f/matK_1R_KIM R. C. amplification of ITS 5a_F/ITS 4_R (ITS1). D. Amplification of S2f/S3R (ITS2). Numbers from 1 to 3 are replicas of DNA of each species. + is the positive control for PCR amplification (DNA extracted from banana leaves). M is the 100 bp DNA Ladder (Cat\# G2101, Promega, Madison, WI, USA)

\section{Molecular barcode of Malva sylvestris and M. pseudolavatera}

As a complement analysis for characterization and identification of the Malva samples, PCR for the molecular barcodes $r b c \mathrm{~L}, m a t \mathrm{~K}$, ITS1 and ITS2 was performed. Amplicons were detected for all the molecular barcodes and the two Malva species (Figure 5). Sequences were submitted to the GenBank (Table 2).

Malva sequences were queried in the GenBank for the $r b c \mathrm{~L}, m a t \mathrm{~K}$ and ITS. After alignment of the barcodes sequences from the GenBank with the $M$. sylvestris and $M$. pseudolavatera samples from Ecuador, the best model for phylogenetic analysis was encountered (T92 for $r b c \mathrm{~L}$, $\mathrm{T} 92+\mathrm{G}$ for $m a t \mathrm{~K}$, and $\mathrm{K} 2$ for ITS). The phylogenetic analysis revealed that for the barcode $r b c \mathrm{~L}$, most of the Malva spp. are clustered including the $M$. sylvestris and $M$. pseudolavatera, while for the Alcea rosea (accessions MK525146, KM360621, MG249560) and Althaea ludwigii (accessions KX282527, KX282525, KX282526), the sequences are grouped in different clades. A similar pattern was observed in $m a t \mathrm{~K}$. On the other hand, the concatenated sequence of the ITS (ITS1 and ITS2) revealed the formation of different clades in specific species of Malva (Figure 6). The M. pseudolavatera from Ecuador (accession MH513499) grouped with several $M$. dendromorpha accessions (EF419468, EF419467, EF419466, EF419469, AF303020) with a bootstrap value of 100 . 


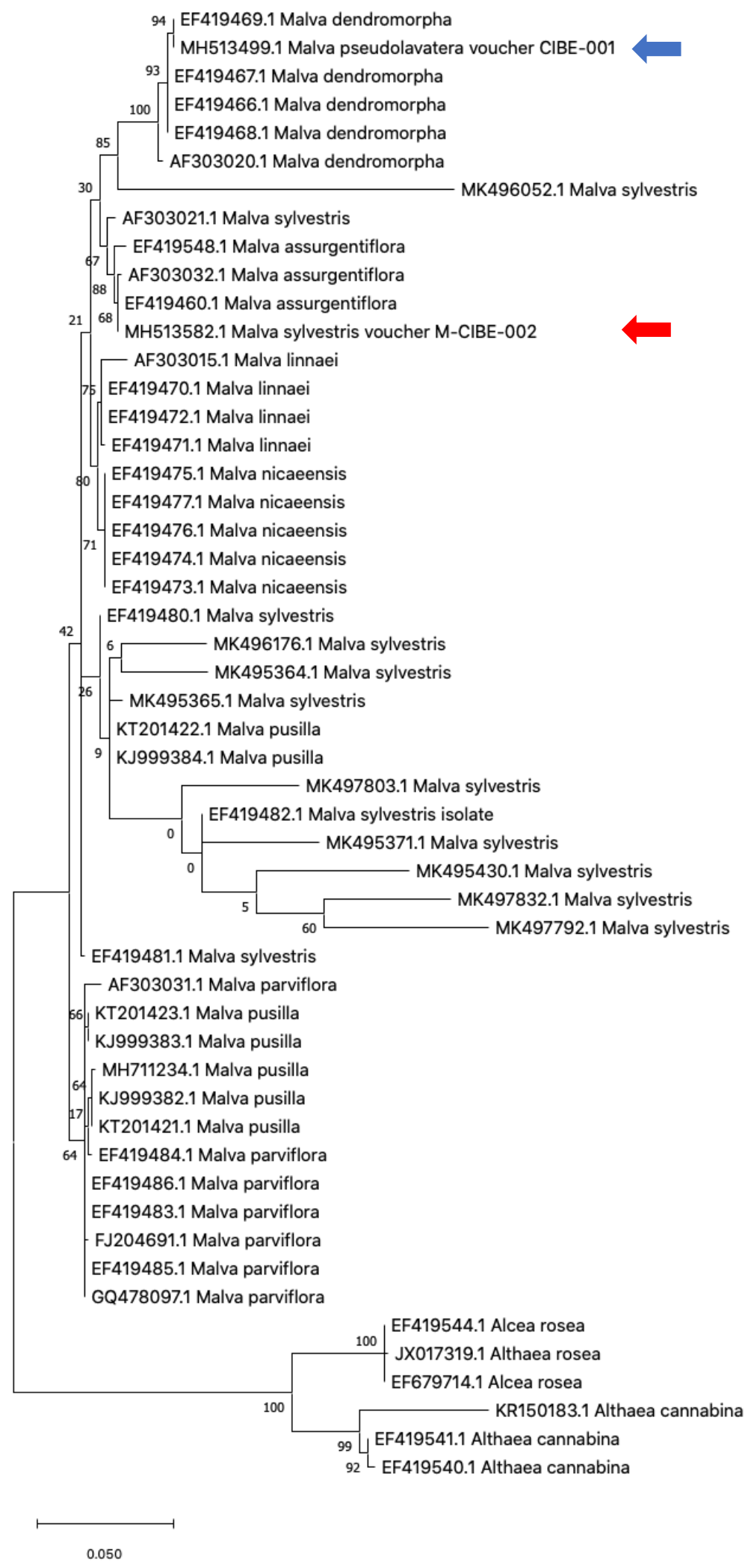

Figure 6. Phylogenetic tree of the ITS region with accessions from the Malva spp. and the Subfamily Malvoideae (genera Alcea and Althaea). Blue arrow and red arrow indicate M. pseudolavatera and M. sylvestris from Ecuador, respectively. The Maximum Likelihood method based on Kimura 2-parameter model was used. Bootstrap test with 100 replicates was performed. Scale represents number of substitutions per site. 
Table 3. Variable sites of the alignment between concatenated ITS1 and ITS2 from Malva pseudolavatera (accession numbers MH513499, MH513596) and Malva sylvestris (accession numbers MH513582, MH517024)

\begin{tabular}{lcc}
\hline $\begin{array}{l}\text { Nucleotide } \\
\text { position }\end{array}$ & $\begin{array}{c}\text { Nucleotide } \\
\text { pseudolavatera }\end{array}$ & $\begin{array}{c}\text { Nucleotide } \\
\text { sylvestris }\end{array}$ \\
\hline 70 & $\mathrm{M}$ & $\mathrm{A}$ \\
100 & $\mathrm{C}$ & $\mathrm{A}$ \\
139 & $\mathrm{~A}$ & $\mathrm{G}$ \\
163 & $\mathrm{~A}$ & $\mathrm{G}$ \\
179 & $\mathrm{~T}$ & $\mathrm{G}$ \\
180 & $\mathrm{C}$ & $\mathrm{T}$ \\
194 & $\mathrm{C}$ & $\mathrm{T}$ \\
197 & $\mathrm{~T}$ & $\mathrm{C}$ \\
212 & $\mathrm{C}$ & $\mathrm{T}$ \\
273 & $\mathrm{C}$ & $\mathrm{T}$ \\
291 & $\mathrm{C}$ & $\mathrm{A}$ \\
292 & $\mathrm{G}$ & $\mathrm{T}$ \\
297 & $\mathrm{~A}$ & $\mathrm{G}$ \\
299 & $\mathrm{~A}$ & $\mathrm{G}$ \\
301 & $\mathrm{~A}$ & $\mathrm{G}$ \\
302 & $\mathrm{C}$ & $\mathrm{G}$ \\
303 & $\mathrm{~A}$ & $\mathrm{G}$ \\
308 & $\mathrm{~A}$ & $\mathrm{C}$ \\
520 & $\mathrm{~A}$ & $\mathrm{C}$ \\
531 & $\mathrm{~T}$ & $\mathrm{~T}$ \\
590 & $\mathrm{C}$ & $\mathrm{G}$ \\
600 & $\mathrm{~T}$ & $\mathrm{~T}$ \\
605 & $\mathrm{~A}$ & $\mathrm{C}$ \\
662 & $\mathrm{C}$ & $\mathrm{G}$ \\
700 & $\mathrm{~T}$ & \\
704 & $\mathrm{~A}$ & \\
\hline
\end{tabular}

Malva sylvestris from Ecuador (accession MH513582) grouped with M. assurgentiflora accessions (EF419548, AF303032, EF419460) and one accession of M. sylvestris (AF303021) with a bootstrap value of 67 (Figure 6). Other M. sylvestris accessions were grouped in other clades but showed low bootstrap values $(<60)$. When comparing the ITS sequences between $M$. sylvestris with $M$. pseudolavatera from Ecuador, a total of 26 variables sites were found in an alignment of 872 nucleotides of the concatenated ITS region (ITS1 and ITS2, Table 3). In the same alignment, one gap was observed at position 325 for $M$. pseudolavatera. Therefore, the ITS region was more informative than the $r b c \mathrm{~L}$ and $m a t \mathrm{~K}$ to discriminate against different species.

Other studies recommend the use of ITS sequences for discriminating between species. For instance, the ITS2 region is suggested as a barcode for species identification over $r b c \mathrm{~L}$ and $m a t \mathrm{~K}$ (Techen et al. 2014; Zhang et al. 2016). ITS sequences in combination with other barcodes (rpoC1, psbA-trnH) were useful for identification at the genus level in Marrakech market for medicinal plants in southern Morocco (Kool et al. 2012); while the molecular barcodes psbA-trnH and ITS sequences discriminate plant species in natural health products in Southern India (Santhosh et al. 2015). Furthermore, the use of the ITS2 sequence successfully identified medicinal plants as showed for Trachelospermum jasminoides (Yu et al. 2017).
DNA barcoding was successfully useful for detection of mislabeling in herbal products using the loci combination $r b c \mathrm{~L}+\mathrm{ITS} 2$ (Kool et al. 2012); therefore, the use of molecular barcodes should be implemented in the herbal industry for proper labeling and authentication of plant species (Kool et al. 2012; Santhosh et al. 2015; Urumarudappa et al. 2019), being the ITS region more suitable for discrimination between species (Li et al. 2013; Zhou et al. 2014; Ganie et al. 2015; Intharuksa et al. 2020). However, more than one barcode sequence should be implemented for accurate species identification in herbal ingredients; furthermore, DNA barcoding should be complement with omics tools including transcriptomics, proteomics, and metabolomics (Mishra et al. 2016); or including NMR spectroscopic (Urumarudappa et al. 2016). Different challenges should be considered for proper plant species identification in the medicinal plant market. For instance, DNA extraction and amplicon size in PCR should be considered for analysis, as processed medicinal products have a direct effect in DNA extraction and PCR efficiency (reviewed by Techen et al. 2014). However, independent of the tissue, age of plant and environmental factors, the use of molecular barcode sequences is reliable for the identification of medicinal plants (Techen et al. 2004).

Before this study, the micro-morphological and barcode sequences of the Malva species cultivated in Ecuador had not been reported before. Differences were encountered at the micro-morphological and genetic levels for ITS region for $M$. pseudolavatera and $M$. sylvestris, corroborating taxonomic classification, while for the $r b c \mathrm{~L}$ and $m a t \mathrm{~K}$ sequences discrimination between both species could not be established. Further chemical, pharmacological and phylogenetic studies could be performed in Malva species for medicinal purposes in Ecuador.

\section{ACKNOWLEDGEMENTS}

The authors declare that they have no competing interests.

\section{REFERENCES}

Ajmal AM, Gyulai G, Hidvégi N, Kerti B, Al Hemaid FMA, Pandey AK, Lee J. 2014. The changing epitome of species identification - DNA barcoding. Saudi J Biol Sci 21 (3): 204-231. DOI: 10.1016/j.sjbs.2014.03.003.

Blunden G, Patel AV, Armstrong NJ, Gorham J. 2001. Betaine distribution in the Malvaceae. Phytochemistry 58: 451-454.

Bustamante K, Santos-Ordóñez E, Miranda M, Pacheco R, Gutiérrez Y, Scull R. 2019. Morphological and molecular barcode analysis of the medicinal tree Mimusops coriacea (A.DC.) Miq. collected in Ecuador. Peer J 7: e7789. DOI: 10.7717/peerj.7789.

Cheng T, Xu C, Lei L, Li C, Zhang Y, Zhou S. 2016. Barcoding the kingdom Plantae: new PCR primers for ITS regions of plants with improved universality and specificity. Mol Ecol Resour 16 (1): 138149. DOI: 10.1111/1755-0998.12438.

Costion C, Ford A, Cross H, Crayn D, Harrington M, Lowe A. 2011. Plant DNA barcodes can accurately estimate species richness in poorly known floras. PLoS One 6 (11): e26841. DOI: 10.1371/journal.pone.0026841. 
Dasmahapatra KK, Mallet J. 2006. Taxonomy: DNA barcodes: recent successes and future prospects. Heredity 97 (4): 254-255. DOI: $10.1038 /$ sj.hdy. 6800858

de la Torre L, Navarrete H, Muriel PM, Macía MJ, Balslev H. 2008. Enciclopedia de las Plantas Útiles del Ecuador. Quito \& Aarhus, Quito.

Ganie SH, Upadhyay P, Das S, Prasad Sharma. 2015. Authentication of medicinal plants by DNA markers. Plant Gene 4: 83-99.

Gasparetto JC, Ferreira MCA, Hayashia SS, Fleith OM, Pontarolo R. 2012. Ethnobotanical and scientific aspects of Malvasylvestris L.: a millennial herbal medicine. J Pharm Pharmacol 64 (2): 172-189. DOI: 10.1111/j.2042-7158. 2011. 01383.x.

Gattuso MA, Gattuso SJ. 1999. Manual de procedimientos para el análisis de drogas en polvo. Editorial de la Universidad Nacional de Rosario, Urquiza.

Ghorbani A, Saeedi Y, de Boer HJ. 2017. Unidentifiable by morphology: DNA barcoding of plant material in local markets in Iran. PLoS ONE 12 (4): e0175722. DOI: 10.1371/journal.pone.0175722.

Hebert PDN, Cywinska A, Ball SL, deWaard JR. 2003. Biological identifications through DNA barcodes. Proc R Soc Lond B 270: 313 321.

Intharuksa A, Sasaki Y, Ando H, Charoensup W, Suksathan R, Kertsawang K, Sirisa-ard P, Mikage M. 2020. The combination of ITS2 and psbA-trnH region is powerful DNA barcode markers for authentication of medicinal Terminalia plants from Thailand. J Nat Med 74 (1): 282-293. DOI: 10.1007/s11418-019-01365-w

Kool A, de Boer HJ, Krüger Å, Rydberg A, Abbad A, Björk L, Martin G. 2012. Molecular identification of commercialized medicinal plants in Southern Morocco. PLoS ONE 7 (6): e39459. DOI: 10.1371/journal.pone.0039459

Li X, Wang B, Han R, Zheng Y, Yin HY, Xu L. 2013. Identification of medicinal plant Schisandra chinensis using a potential DNA barcode ITS2. Acta Soc Bot Pol 82: 283-288.

Miranda MM, Cuéllar AC. 2000. Manual de prácticas de laboratorio. Farmacognosia y productos naturales, Ciudad Habana, Cuba.

Mofid B, Rezaeizadeh H, Jaladat AM, Atarzadeh F, Moeini R, Motevalian A, Mosalaie A, Farhan F, Rakhsha A, Kashi AS. 2015. Preventive effect of Malva on urinary toxicity after radiation therapy in prostate cancer patients: A multi-centric, double-blind, randomized clinical trial. Electron Physician 7 (5): 1220-1226. DOI: 10.14661/1220

Nasiri E, Hosseinimehr SJ, Azadbakht M, Akbari J, Enayati-Fard R, Azizi S. 2015. Effect of Malva sylvestris cream on burn injury and wounds in rats. Avicenna J Phytomed 5 (4): 341-354.
Pacheco Coello R, Pestana Justo J, Factos Mendoza A, Santos Ordoñez E. 2017. Comparison of three DNA extraction methods for the detection and quantification of GMO in Ecuadorian manufactured food. BMC Res Notes 10: 758. DOI: 10.1186/s13104-017-3083-x.

Razavi SM, Zarrini G, Molavi G, Ghasemi G. 2011. Bioactivity of Malva sylvestris L., a medicinal plant from Iran. Iran J Basic Med Sci 14 (6): 574-579.

Romitelli I, Martins MBG. 2013. Comparison of leaf morphology and anatomy among Malva sylvestris ("gerânio-aromático"), Pelargonium graveolens ("falsa-malva") and Pelargonium odoratissimum ("gerânio-de-cheiro"). Rev Bras Pl Med 15 (1): 91-97.

Santhosh KJU, Krishna V, Seethapathy GS, Senthilkumar U, Ragupathy S, Ganeshaiah KN, Ganesan R, Steven G Newmaster, Ravikanth G, Uma Shaanker R. 2015. DNA barcoding to assess species adulteration in raw drug trade of "Bala" (genus: Sida L.) herbal products in South India. Biochem Syst Ecol 61: 501-509. DOI: 10.1016/j.bse.2015.07.024.

Stecher G, Tamura K, Kumar S. 2020. Molecular Evolutionary Genetics Analysis (MEGA) for macOS. Mol Biol Evol 37 (4): 1237-1239. DOI: $10.1093 / \mathrm{molbev} / \mathrm{msz} 312$.

Techen N, Parveen I, Pan Z, Khan IA. 2014. DNA barcoding of medicinal plant material for identification. Curr Opin Biotechnol 25: 103-110.

Urumarudappa SK, Gogna N, Newmaster SG, Venkatarangaiah K, Subramanyam R, Saroja SG, Gudasalamani R, Dorai K, Ramanan US. 2016. DNA barcoding and NMR spectroscopy-based assessment of species adulteration in the raw herbal trade of Saraca asoca (Roxb.) Willd, an important medicinal plant. Intl J Legal Med 130 (6): 1457-1470. DOI: 10.1007/s00414-016-1436-y.

Urumarudappa SKJ, Tungphatthong C, Sukrong S. 2019. Mitigating the Impact of Admixtures in Thai Herbal Products. Front Pharmacol 10: 1205. DOI: 10.3389/fphar.2019.01205.

Yu N, Wei YL, Zhang X, Zhu N, Wang YL, Zhu Y, Zhang HP, Li FM, Yang L, Sun JQ, Sun AD. 2017. Barcode ITS2: a useful tool for identifying Trachelospermum jasminoides and a good monitor for medicine market. Sci Rep 7 (1): 5037. DOI: 10.1038/s41598-01704674-w.

Zhang D, Jiang B, Duan L, Zhou N. 2016. Internal Transcribed Spacer (ITS), an ideal DNA barcode for species discrimination in Crawfurdia Wall. (Gentianaceae). Afr J Tradit Compl Altern Med 13 (6): 101106.

Zhou J, Wang W, Liu M, Liu Z. 2014. Molecular authentication of the traditional medicinal plant Peucedanum praeruptorum and its substitutes and adulterants by DNA-barcoding technique. Pharmacogn Mag 10: 385-390. 